\title{
Normal values for respiratory resistance using forced oscillation in subjects $>65$
} years old

\author{
Y.F. Guo*, F. Herrmann*, J.P. Michel* and J-P. Janssens\#
}

ABSTRACT: The aim of the present study was to determine reference values and predictive variables for respiratory impedance (Zrs) by the forced oscillation technique (FOT) in subjects aged $>65$ yrs.

The investigation involved a prospective study of nonsmoking subjects, with normal forced expiratory volumes. The Zrs parameters, which included average resistance between 4-16 $\mathrm{Hz}$ $(R 4-16)$, average resistance between 4-30 Hz $(R M)$, resonant frequency (FN), capacitance $(C)$ and inertance (I), were measured along with forced expiratory manoeuvres. Every subject had each parameter measured in the same sequence using FOT and spirometry.

A total of 223 subjects aged $83 \pm 8$ yrs were included in the study. The mean values for forced expiratory volume in one second $\left(F E V_{1}\right) \%$ predicted were $110 \pm 23$. The forced vital capacity (FVC) \% pred was $114 \pm 21$ and the FEV1/FVC \% pred was $112 \pm 11$. The mean values for the Zrs parameters were: $R 4-16: 0.25 \pm 0.07 \mathrm{kPa} \cdot \mathrm{s}^{-1} \cdot \mathrm{L}^{-1} ; \mathrm{RM}: 0.25 \pm 0.06 \mathrm{kPa} \cdot \mathrm{s}^{-1} \cdot \mathrm{L}^{-1}$; $\mathrm{FN}: 11.0 \pm 2.8 \mathrm{~Hz}$; I: $1.17 \pm 0.26 \mathrm{~Pa} \cdot \mathrm{L}^{-1} \cdot \mathrm{s}^{-2}$; and $\mathrm{C}: 20.5 \pm 9.0 \mathrm{~mL} \cdot \mathrm{hPa}^{-1}$. In multiple regression models adjusted for age, sex, height and weight, height was the most influential predictor for Zrs parameters based on the magnitude of the regression coefficient.

In conclusion, it was found that height was the best predictor for respiratory impedance parameters. Contribution of age and weight was negligible. However, the level of predictability for respiratory impedance parameters by regression equations was low.

KEYWORDS: Aged $>65$ years, aged $>80$ years, elderly, forced oscillation technique, normal values, respiratory resistance

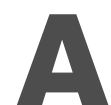
s both asthma and chronic obstructive lung disease (COPD) are under-diagnosed in older patients, pulmonary function tests are a necessary adjunct to clinical assessment in elderly subjects with respiratory symptoms [1, 2]. Although spirometry is the gold standard for the diagnosis of obstructive lung disease, it is sometimes difficult to perform in older subjects due to reduced cooperation, fatiguability or cognitive impairment [3, 4]. Indeed, feasibility of spirometry may drop to $<50 \%$ in hospitalised or institutionalised elderly subjects $[3,5]$. Few techniques are available for testing respiratory function during tidal breathing, thus avoiding forced expiratory manoeuvres. The forced oscillation technique (FOT) is of special interest because it is noninvasive, requires minimal cooperation, takes little time and can be easily repeated, especially in children and older subjects who cannot accomplish forced

For editorial comments see page 563. expiratory manoeuvres in a reproducible manner $[5,6]$. In FOT, pressure oscillations are transmitted to the patient's airway during normal tidal breathing. From the resultant flow and pressure changes, the impedance ( $\mathrm{Zrs})$ of the respiratory system is determined $[7,8]$.

Significant correlations between forced expiratory volumes and FOT have been reported in previous studies [5, 6]. Normative data for Zrs for children and young adults have recently been summarised in a European Respiratory Society (ERS) Task Force report [9]. However, no reference values for the FOT have, to date, been reported in older subjects.

The aim of this study was to determine reference values for respiratory resistance measured by FOT in older, healthy subjects, and to establish which anthropometric variables were significantly predictive of $\mathrm{Zrs}$ parameters within this age group.

\section{AFFILIATIONS}

${ }^{*}$ Dept of Rehabilitation and Geriatrics, and

"Division of Pulmonary Medicine,

Geneva University Hospital, Geneva, Switzerland.

\section{CORRESPONDENCE}

$J-P$. Janssens

Centre antituberculeux

Hôpital Cantonal Universitaire

1211 Geneva 14

Switzerland

Fax: 41223729929

E-mail:

Jean-Paul.Janssens@hcuge.ch

Received:

January 302005

Accepted after revision:

May 302005 


\section{PATIENTS AND METHODS Patients}

This study was performed in a 304-bed intermediate-care geriatric teaching hospital, between October 2001 and April 2004. Patients were considered for the study if they had not been hospitalised because of cardiac or respiratory disorders, they had no signs or symptoms suggestive of an acute or chronic cardiac, respiratory, or neuromuscular disease, and if chest roentgenograms (performed routinely upon admission) showed no signs of parenchymal, pleural or diaphragmatic disorders. Patients were excluded if they had any cognitive and/or sensory impairment that could interfere with pulmonary function testing or if they could not assume a sitting position. Nonsmoking subjects accepting to participate in the study were referred for pulmonary function testing. They were subsequently included if they had successfully performed measurement of forced expiratory manoeuvres according to the American Thoracic Society (ATS) recommendations [10], and if the results were within the normal range according to the ERS criteria [11]: forced expiratory volume in one second (FEV1) and forced vital capacity (FVC) being $>80 \%$ predicted; and $\mathrm{FEV} 1 / \mathrm{FVC}$ being $>88 \%$ pred for males and $89 \%$ pred for females.

The study protocol was approved by the Ethics Committee of the University Hospital of Geneva (Geneva, Switzerland).

\section{Assessment of respiratory function}

FOT measurements were performed before spirometry to avoid any possible increase in bronchial reactivity generated by repeated forced expiratory manoeuvres and to minimise the influence of fatigue on the FOT results.

\section{Measurement of forced expiratory volumes and flows}

The Oscilink $®$ combined spirometer/FOT instrument (Datalink®, Montpellier, France) was used to measure FEV1, $\mathrm{FVC}$, and FEV1/FVC ratio (FEV1\%). Patients were in a seated position and a noseclip was used. Measurements were repeated a minimum of three times, only the highest FEV1 and FVC results were included in the analyses. FEV1, FVC and FEV1/FVC results were expressed as \% pred, according to prediction equations by QUANJER et al. [12] (extrapolated from subjects aged 18-70 yrs). Acceptance of measurements was subject to ATS criteria [10].

\section{Measurement of respiratory impedance}

The theoretical basis for FOT measurements has recently been extensively reviewed [9]. FOT allows the measurement of Zrs. In brief, forced oscillations $(4-30 \mathrm{~Hz}$ ) are applied at the mouth via a loudspeaker. Airflow is measured with a pneumotachograph attached to the mouthpiece. Pressure and flow signals are analysed by Fast Fourier Transform to calculate the impedance of the respiratory system at all oscillatory frequencies. Zrs embodies the in-phase and out-of-phase relationships between pressure and airflow. The in-phase component, or real part of $\mathrm{Zrs}$, resistance $(R \mathrm{rs})$, is related to the resistive properties of the respiratory system. The out-of-phase or imaginary part of $Z \mathrm{rs}$, reactance $\left(\mathrm{Xrs}_{\mathrm{rs}}\right.$, is related to elastic and inertial properties of the respiratory system. In healthy subjects, Rrs is virtually frequency-independent in the range of frequencies studied (4-30 Hz, range recommended by the ERS task force)
[9]. $\mathrm{X}_{\mathrm{rs}}$ increases with increasing frequency, from negative to positive values. The frequency at which $\mathrm{X}_{\mathrm{rs}}$ equals zero is the resonant frequency (FN) of the respiratory system, which increases in obstructive airway diseases $[5,13]$.

The Oscilink ${ }^{\circledR}$ software determines, for each patient, the following parameters: 1) the real part of $Z_{\mathrm{rs}}$ : the average resistance between $4-30 \mathrm{~Hz}\left(R \mathrm{M}, \mathrm{kPa} \cdot \mathrm{s}^{-1} \cdot \mathrm{L}^{-1}\right)$, the average resistance between $4-16 \mathrm{~Hz}\left(R 4-16, \mathrm{kPa} \cdot \mathrm{s}^{-1} \cdot \mathrm{L}^{-1}\right)$; and 2$)$ the imaginary part of $\mathrm{Zrs}$ : the $\mathrm{FN}(\mathrm{Hz})$, capacitance $\left(\mathrm{C}, \mathrm{mL} \cdot \mathrm{hPa}^{-1}\right)$ and inertance $\left(\mathrm{I}, \mathrm{Pa} \cdot \mathrm{L}^{-1} \cdot \mathrm{s}^{-2}\right)$.

Zrs measurements were performed with the Oscilink ${ }$ spirometer-FOT instrument, derived from a prototype described by CARVAlHAES-NetO et al. [3] according to the recent recommendations of the ERS Task Force [9]. A calibration of pressure and flow was performed before each new patient. During measurements, the patients were equipped with a noseclip, seated comfortably with their head in a neutral position [14], and breathed through a mouthpiece. Both cheeks were supported by the hands of the technician [15]. Care was taken to avoid flexion of the head. Patients were asked to breathe quietly at the functional residual capacity (FRC) level and avoid swallowing. A pseudo-random noise signal mixing 27 harmonics of $1 \mathrm{~Hz}$ between $4-30 \mathrm{~Hz}$ was generated by a loudspeaker and superimposed on the patients' spontaneous breathing. Two "Validyne" pressure transducers (DP $45 \pm 2 \mathrm{cmH}_{2} \mathrm{O}$; Validyne, Northridge, CA, USA) were used for $\mathrm{Zrs}$ measurements, one measured pressure at the mouth, the other was connected to a Hans-Rudolf pneumotachograph (4700; Hans Rudolph, Kansas City, MO, USA), which recorded mouth flow. Both signals were filtered to reject low $(<3 \mathrm{~Hz})$ and high frequencies and processed using a Fourier analysis. Recorded data were sampled at $128 \mathrm{~Hz}$, and averaged over four consecutive breathing periods of $4 \mathrm{~s}$. Particular attention was given to monitoring resting ventilation, and excluding data with irregular breathing, coughing, hyperventilation, glottis closure, swallowing, apnoea, or leaks around the mouthpiece. A minimum of 3-5 technically acceptable consecutive measurements were performed [9]. Respiratory resistance measurements were retained for analysis if the coefficient of variation of three consecutive measurements was $\leqslant 15 \%$. As recommended by the ERS task force, results of Zrs measurements are presented as mean $\pm \mathrm{SD}$ of successive measurements with their coefficient of variation $(\mathrm{CV})$ given as an index of reliability and repeatability $[9,16]$. The CV for FOT indices previously reported in healthy adults is between 5-15\% [17-21]. The Oscilink ${ }_{\circledR}$ software used in this study did not include a coherence function (which can reveal the discrepancy of repeated Zrs measurements, especially in the low frequency range). However, the use of a coherence function is optional when CVs of Zrs parameters are reported $[9,16]$.

\section{Statistical analysis}

Statistical analyses were performed using Stata 8.2 software. Data are presented as mean \pm SD unless specified otherwise. For all tests ( $Z_{r s}$ and spirometry), the CV of the results is reported. The Stata command "sktest", based on a combination of skewness and kurtosis test, was used to assess normality of the distribution of the $\mathrm{Zrs}$ parameters studied. Usual transforms were applied to normalise non-Gaussian 
variables. Univariate and multiple regression analyses adjusted for age, sex, weight and height were applied to identify the association of these variables with $\mathrm{Zrs}$ parameters.

\section{RESULTS}

During the study period, 223 nonsmoking subjects were enrolled (mean \pm SD (range) $83 \pm 8(65-100)$ yrs). A total of 180 $(81 \%)$ were never-smokers. Among them, 77 (35\%) were male (81 \pm 7 (range 65-94) yrs), and 146 (65\%) were female (84 \pm 8 (range $65-100)$ yrs). All subjects were Caucasians. The age distribution is shown in figure 1.

The average within-test variability of repeated measurements of Zrs expressed as CV were: R4-16: 7.6\%; RM: $6.4 \%$; FN: 5.9\%; I: $8.3 \%$; and C: $11.8 \%$. CVs of forced expiratory manoeuvres were: FVC: $5.8 \%$; FEV1: 5.2\%; and FEV1/FVC: $4.2 \%$.

Values by sex are reported in table 1. Average values (mean $\pm \mathrm{SD})$ for spirometry for all patients were: FVC: $2.35 \pm 0.75 \mathrm{~L}$, range: $1.0-4.2 \mathrm{~L}$; FVC \% pred: $114 \pm 21 \%$, range 75-199\%; FEV1: $1.92 \pm 0.62$ L, range: 0.8-3.8 L; FEV1 \% pred: $110 \pm 23 \%$, range $73-201 \%$; FEV1/FVC (calculated on the basis of the two highest values obtained for FEV1 and FVC): $82 \pm 8 \%$, range $66-100 \%$; and $\mathrm{FEV} 1 / \mathrm{FVC} \%$ pred: $112 \pm 11 \%$, range $93-$ $141 \%$ [12].
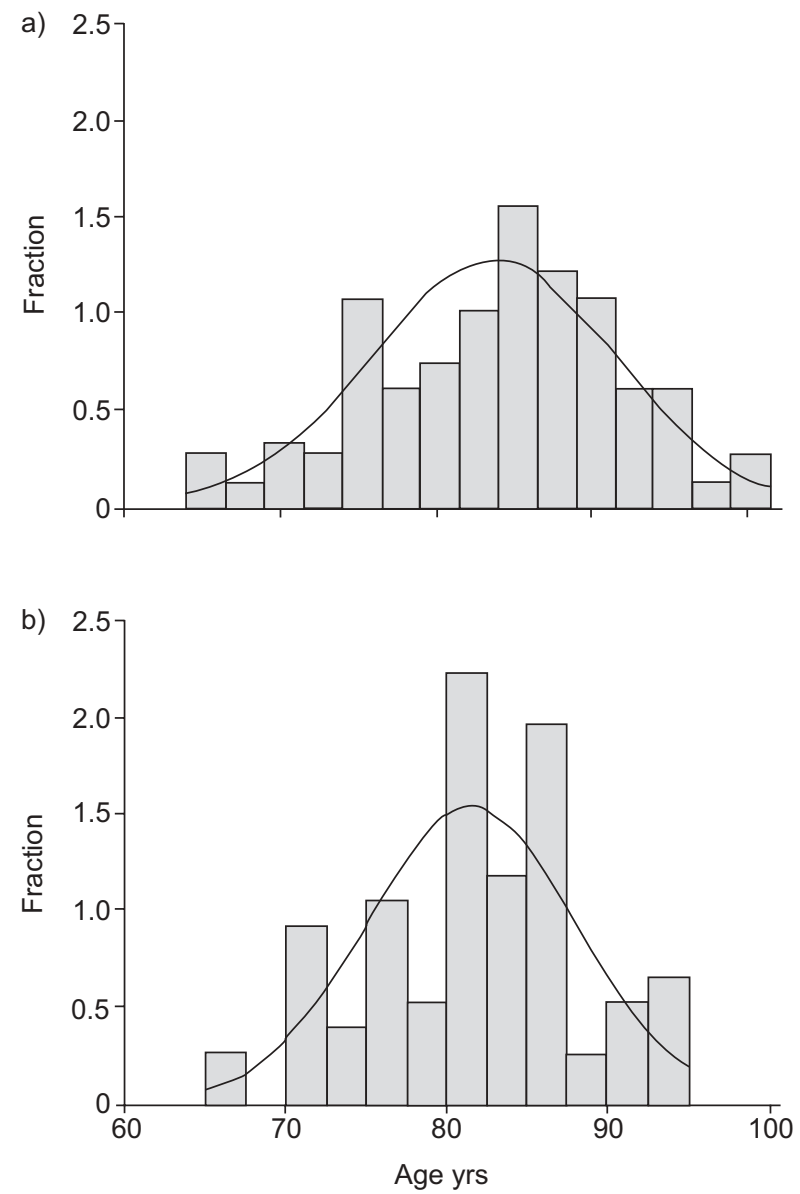

FIGURE 1. Age distribution for the population studied: a) females ( $n=146)$, and b) males $(n=77)$.

\begin{tabular}{|c|c|c|c|}
\hline \multirow[t]{2}{*}{ TABLE 1} & \multicolumn{3}{|c|}{$\begin{array}{l}\text { Anthropometric data and pulmonary function } \\
\text { tests }\end{array}$} \\
\hline & Males & Females & p-values \\
\hline Subjects $n$ & 77 & 146 & \\
\hline Age yrs & $81.5 \pm 6.5$ & $83.7 \pm 7.9$ & 0.02 \\
\hline Height $m$ & $1.69 \pm 0.08$ & $1.56 \pm 0.08$ & $<0.001$ \\
\hline Weight kg & $71.3 \pm 12.3$ & $59.3 \pm 11.8$ & $<0.001$ \\
\hline$B M I \mathbf{~ g g} \cdot \mathbf{m}^{-2}$ & $25.2 \pm 3.8$ & $24.4 \pm 4.9$ & $>0.05$ \\
\hline FEV $1 \%$ pred & $104 \pm 18(80-141)$ & $111 \pm 24(80-174)$ & 0.013 \\
\hline FVC \% pred & $97 \pm 16(83-173)$ & $108 \pm 20(83-164)$ & $<0.001$ \\
\hline $\mathrm{FEV}_{1 / \mathrm{FVC}} \%$ pred & $114 \pm 13(89-145)$ & $108 \pm 12(89-136)$ & 0.001 \\
\hline$R 4-16 \mathrm{kPa} \cdot \mathrm{s}^{-1} \cdot \mathrm{L}^{-1}$ & $0.222 \pm 0.062$ & $0.266 \pm 0.065$ & $<0.001$ \\
\hline$R \mathrm{M} \mathrm{kPa} \cdot \mathrm{s}^{-1} \cdot \mathrm{L}^{-1}$ & $0.223 \pm 0.057$ & $0.269 \pm 0.059$ & $<0.001$ \\
\hline FN Hz & $10.0 \pm 2.3$ & $11.6 \pm 2.9$ & $<0.001$ \\
\hline $\mathrm{C} \mathrm{mL} \cdot \mathrm{hPa}^{-1}$ & $23.15 \pm 8.60$ & $18.97 \pm 8.83$ & 0.005 \\
\hline $\mathrm{Pa} \cdot \mathrm{L}^{-1} \cdot \mathrm{s}^{-2}$ & $1.20 \pm 0.22$ & $1.15 \pm 0.28$ & 0.14 \\
\hline
\end{tabular}

Data are presented as mean \pm SD or mean \pm SD (range), unless otherwise stated. BMI: body mass index; FEV1: forced expiratory volume in one second; \% pred: percentage predicted; FVC: forced vital capacity; R4-16: mean resistance between 4-16 Hz; RM: mean resistance between 4-30 Hz; FN: resonant frequency; C: capacitance; I: inertance.

The average values for $R$ rs parameters were: $R 4-16$ : $0.251 \pm 0.07 \mathrm{kPa} \cdot \mathrm{s}^{-1} \cdot \mathrm{L}^{-1} ; R \mathrm{M}: 0.254 \pm 0.06 \mathrm{kPa} \cdot \mathrm{s}^{-1} \cdot \mathrm{L}^{-1}$ and for $\mathrm{Xrs}$ parameters were: FN: $11.0 \pm 2.8 \mathrm{~Hz} ; \mathrm{I}: 1.17 \pm 0.26 \mathrm{~Pa} \cdot \mathrm{L}^{-1} \cdot \mathrm{s}^{-2}$; C: $20.47 \pm 8.96 \mathrm{~mL} \cdot \mathrm{hPa}^{-1}$. Rrs values were, on average, slightly lower than those reported in previous studies of younger healthy adults (fig. 2; table 2) [13, 17, 22-25]. In females, Rrs values were slightly higher than in males, as reported in younger healthy adults [23-25]. Table 1 shows small, but statistically significant, differences in $Z$ rs values between male and female subjects.

Univariate analyses were computed to test for significant relationships between sex, age, height and weight and $X_{r s}$ parameters. Significant results are shown in table 3 . Zrs parameters were normalised (natural log transformation for R4-16 and RM, reciprocal transformation for FN). Only height and sex showed weak, although significant, inverse relationships with Zrs parameters. Furthermore, multivariate analyses were performed using age, sex, height and weight as independent variables, to determine predictive equations for Zrs parameters. Predictive equations were computed by multiple regression analysis (table 4; Appendix). The contribution of age was nonsignificant for R4-16, and negligible for $R M$ and FN. Although significant, the contribution of weight to the regression equations was not relevant. Height showed the strongest correlation with $R 4-16, R M$ and FN. Regression equations including sex, age, height and weight predicted $20-23 \%$ of the variability of $R 4-16, R \mathrm{M}$ and $\mathrm{FN}\left(\mathrm{r}^{2}\right)$.

\section{DISCUSSION}

This study provides, to the present authors' knowledge, the only reference values available for the assessment of respiratory resistance using the FOT technique in elderly subjects. CVs given as an index of reliability (as recommended by the ERS Task Force) were within the best values reported by others 

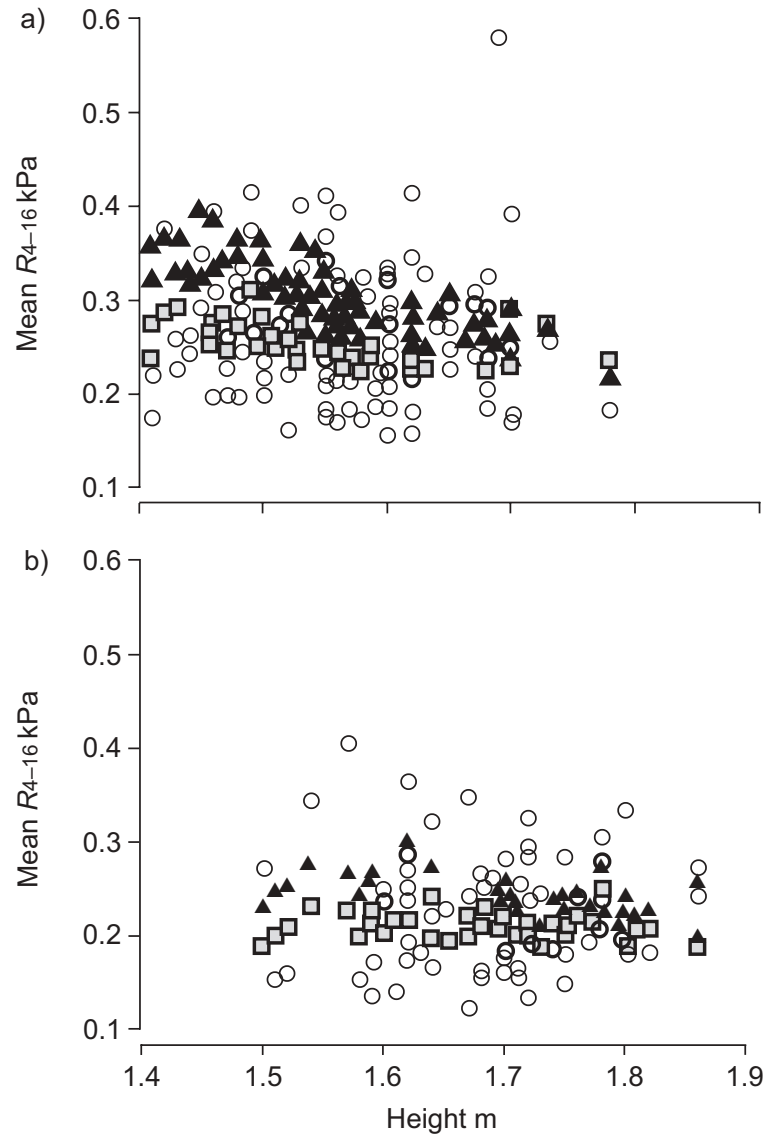

FIGURE 2. Comparison of observed values for mean resistance between 4 $16 \mathrm{~Hz}$ (R4-16; O), predicted values according to PASKER et al. [24] (ب), and predicted values according to the present study $(\square)$ for a) females $(n=146)$, and b) males $(n=77)$. See Appendix for regression equation for $R 4-16$.

$(5-15 \%)[19,20,26]$, and similar to those reported for plethysmographic measurements [9, 27]. Among anthropometric variables analysed, height was the best predictor for $R \mathrm{rs}$ and FN, and contribution of age and weight was either

\begin{tabular}{|c|c|c|c|c|c|}
\hline TABLE 2 & \multicolumn{5}{|c|}{$\begin{array}{l}\text { Resistance values according to prediction } \\
\text { equations from the present study (average } \\
\text { resistance between } 4-30 \mathrm{~Hz} \text { ), and from three } \\
\text { previous studies including younger adults }\end{array}$} \\
\hline \multirow{2}{*}{\multicolumn{2}{|c|}{ Ref. }} & \multicolumn{2}{|c|}{ Males } & \multicolumn{2}{|c|}{ Female } \\
\hline & & $70 \mathrm{yrs}$ & 90 yrs & 70 yrs & 90 yrs \\
\hline \multicolumn{2}{|c|}{ Present study } & 0.233 & 0.215 & 0.272 & 0.251 \\
\hline \multicolumn{2}{|c|}{ PASKER et al. [23] } & 0.269 & 0.269 & 0.305 & 0.305 \\
\hline \multicolumn{2}{|c|}{ PASker et al. [24] } & 0.249 & 0.238 & 0.285 & 0.271 \\
\hline \multicolumn{2}{|c|}{ GovaERTS et al. [25] } & 0.264 & 0.264 & 0.274 & 0.274 \\
\hline
\end{tabular}

Values given are those calculated for males (height: $1.75 \mathrm{~m}$; weight: $80 \mathrm{~kg}$ ) and females (height: $1.55 \mathrm{~m}$; weight: $50 \mathrm{~kg}$ ) aged 70 and $90 \mathrm{yrs}$. Regression equations from the present study yield results which are up to $25 \%$ lower than results from previous studies.

\begin{tabular}{|c|c|c|c|c|c|}
\hline \multirow[t]{2}{*}{ TABL } & \multicolumn{5}{|c|}{$\begin{array}{l}\text { Univariate regressions for respiratory impedance } \\
\text { (Zrs) variables on height and sex }\end{array}$} \\
\hline & Zrs & Coefficient & $95 \% \mathrm{Cl}$ & $r^{2}$ & p-value \\
\hline \multirow[t]{3}{*}{ Height } & In R4-16 & -0.714 & $-1.060--0.368$ & 0.0070 & $<0.001$ \\
\hline & In $R M$ & -0.665 & $-0.986--0.344$ & 0.070 & $<0.001$ \\
\hline & $1 / \mathrm{FN}$ & 0.070 & $0.042-0.098$ & 0.097 & $<0.001$ \\
\hline \multirow[t]{3}{*}{ Sex } & In $R 4-16$ & -0.186 & $-0.255--0.115$ & 0.111 & $<0.001$ \\
\hline & In $R M$ & -0.195 & $-0.259--0.132$ & 0.142 & $<0.001$ \\
\hline & $1 / \mathrm{FN}$ & 0.013 & $0.007-0.0190$ & 0.080 & $<0.001$ \\
\hline
\end{tabular}

Zrs variables were normalised for computation of univariate regressions. 95\% Cl: $95 \%$ confidence intervals; In: natural logarithm; $r^{2}$ : variability of Zrs variables explained by height or sex. R4-16: mean resistance between 4-16 Hz; RM: mean resistance between $4-30 \mathrm{~Hz}$; FN: resonant frequency. $n=223$.

nonsignificant or negligible. Rrs parameters were slightly lower than in younger subjects, and significantly higher in females, as reported in younger adults [23-25]. Interestingly, Rrs values computed with the regression equations provided in this study yielded lower results than predicted values extrapolated from younger subjects [23-25], emphasising the necessity of establishing reference values based on healthy older individuals (table 2).

$\begin{array}{cl}\text { TABLE } 4 & \begin{array}{l}\text { Predictive equations for respiratory impedance } \\ \text { (Zrs) variables derived from multiple regression } \\ \text { analysis }\end{array}\end{array}$

\begin{tabular}{|c|c|c|c|c|c|}
\hline Rrs & Coefficient & SE & $95 \% \mathrm{Cl}$ & p-value & $r^{2}$ \\
\hline In (R4-16) & & & & & 0.21 \\
\hline Age yrs & -0.003 & 0.002 & $-0.007-0.002$ & 0.226 & \\
\hline Sex & -0.188 & 0.044 & $-0.273--0.101$ & $<0.001$ & \\
\hline Height $\mathrm{m}$ & -0.653 & 0.224 & $-1.095--0.211$ & 0.004 & \\
\hline Weight kg & 0.007 & 0.001 & $0.004-0.009$ & $<0.001$ & \\
\hline Constant & 0.491 & 0.434 & $-1.347-0.364$ & 0.259 & \\
\hline In $(R M)$ & & & & & 0.23 \\
\hline Age yrs & -0.004 & 0.002 & $-0.008--0.000$ & 0.034 & \\
\hline Sex & -0.203 & 0.040 & $-0.281--0.124$ & $<0.001$ & \\
\hline Height m & 0.519 & 0.205 & $-0.923--0.115$ & 0.012 & \\
\hline Weight kg & 0.005 & 0.001 & $0.003-0.008$ & $<0.001$ & \\
\hline Constant & -0.467 & 0.397 & $-1.250-0.315$ & 0.240 & \\
\hline $1 / \mathrm{FN}$ & & & & & 0.20 \\
\hline Age yrs & 0.000 & 0.000 & $-0.001--0.000$ & 0.011 & \\
\hline Sex & 0.011 & 0.004 & $0.003-0.018$ & 0.04 & \\
\hline Height m & 0.062 & 0.019 & $0.025-0.098$ & 0.001 & \\
\hline Weight $\mathrm{kg}$ & -0.001 & 0.000 & $-0.001--0.000$ & $<0.001$ & \\
\hline Constant & 0.067 & 0.036 & $-0.004-0.139$ & 0.064 & \\
\hline
\end{tabular}

Zrs variables were normalised for multiple regression analysis (In transformation for mean resistance between 4-30 Hz (RM) and mean resistance between 4$16 \mathrm{~Hz}(R 4-16)$, and 1/FN for resonant frequency). Rrs: resistance; SE: standard error; $95 \% \mathrm{Cl}$ : $95 \%$ confidence interval; $r^{2}$ : variability of $Z$ rs variables explained by age, sex, height or weight. See Appendix for equations. $n=223$; male=1; female $=0$. 
FOT is a simple, noninvasive method for assessing respiratory resistance requiring only minimal cooperation from the patient. The most attractive feature of FOT is that forced oscillations are superimposed on normal tidal breathing, and, thus, FOT does not require repeated forced expiratory manoeuvres. FOT has been studied in infants, children, children with asthma or chronic nocturnal cough, intubated patients [28], patients with restrictive disorders or COPD [29] and in obstructive sleep apnoea patients [30]. Highly significant correlations between results of spirometry and FOT have been reported in previous studies [3, 5, 31].

The interest of FOT in older subjects has been documented in two previous studies [3,5]. CARVALHAES-NETO et al. [3], using a prototype of the FOT instrument used in this study, showed that the feasibility of spirometry was closely related to the degree of cognitive impairment, and dropped as low as $20 \%$ in hospitalised or institutionalised elderly patients, with moderate or severe cognitive impairment. In their study, feasibility of spirometry for the population tested was 40 versus $76 \%$ for FOT. In a previous study, the current authors reported similar results for patients hospitalised in a geriatric teaching hospital. Only $50 \%$ of patients tested could adequately perform spirometry versus $74 \%$ for FOT [5]. In the latter study, FOT identified subjects with obstructive lung disease with a sensitivity and specificity of 76 and $78 \%$, respectively [5]. There are two other techniques for the assessment of airway resistance: body plethysmography, and the "interrupter" technique. In the current authors' experiences, body plethysmography is often difficult to perform in very old subjects, with much lower feasibility rates than spirometry. Indeed, very few studies of normal reference values for total pulmonary capacity measured by plethysmography include subjects aged $>75$ yrs [32]. The interrupter technique is an interesting alternative. The technique is simple, the equipment is portable, measurements are also performed during quiet tidal breathing and cooperation requirements are low [33, 34]. However, a recent study in children suggests a much higher CV than FOT, and a lower sensitivity and specificity than FOT for the detection of obstructive airway disease [35].

In the present study, height and sex were significantly related to FOT parameters, while the contributions of age and weight were either negligible or nonsignificant. Predictability of $R \mathrm{M}$, R4-16 and FN was rather low, with $\mathrm{r}^{2}$ values ranging $0.20-0.23$. The ERS task Force on FOT in clinical practice recently reviewed available references for FOT for children and for younger adults [9]. An overview of regression equations predictive of respiratory resistance in children aged 2-18 yrs showed that height was the only relevant anthropometric variable for predicting Rrs. In healthy adults aged, on average, 26-58 yrs, prediction equations for average resistance included height, weight, and age. Coefficients for age and weight were, however, very low, with height being by far the most significantly predictive anthropometric variable [13, 17, 2325]. Rrs was inversely related to height in most available studies $[17,23,25]$. Unlike most studies in children, sex was also an important predictor of resistance, and significantly improved the strength of the predictive equations. In the present report, average values for $R$ rs in older females are slightly higher than for males. This is in agreement with the results of GOVAERTS et al. [25] and PASKER et al. [23, 24]. One suggested mechanism for this difference is the sex-related difference in lung volumes.

As in healthy adults (in the range of oscillation frequencies applied in this study), there is virtually no frequency dependence of resistance: $R M$ and $R 4-16$ of older subjects can be compared with values obtained in younger adults tested at similar frequencies. Values reported in the present study tend to be slightly lower than values reported in younger adults. Physiological ageing of the respiratory system is associated with minor changes in the flow-volume curves, reflecting increased airway resistance of smaller airways, thus, an increase in Rrs could have been expected [36]. However, in adults, small peripheral airways contribute marginally to total airway resistance and, therefore, age-related changes in peripheral airways are not reflected by changes in Rrs. Three possible explanations for lower airway resistance (Raw) in older subjects have been suggested. First, Raw decreases when elastic recoil pressure of the lung or of the respiratory system increases (by distending the airways), and ageing is associated with a decreased compliance of the respiratory system [36, 37]. Secondly, Raw decreases at larger lung volumes and ageing is associated with an increase in FRC [38, 39]. Finally, an increase in inequality of ventilatory time constants with age may contribute to the relationship between age and Raw [39].

There are a few potential drawbacks to this study. The first drawback relates to the population selected as older healthy subjects. These subjects had been admitted to a geriatric intermediate-care teaching hospital, although for noncardiac or respiratory disorders. As such, pulmonary function testing could have been compromised by nutritional status, decreased muscular strength, or comorbidities. However, the nutritional status of patients included was in the normal range (table 1) and relevant comorbidities would have affected the results of spirometric testing in as much as spirometry is highly collaboration dependent. Also, the presence of a normal FEV1, FVC, and FEV1/FVC at time of FOT testing reasonably excludes any significant obstructive or restrictive respiratory disorder.

The second possible limitation might be the nonexclusion of ex-smokers. Prevalence of previous smoking in a geriatric population is estimated to be $49 \%$ in the older male population, and $\sim 20 \%$ in older females [40]. The main impact of previous smoking on pulmonary function testing is the presence, in susceptible individuals, of airway obstruction (detected by spirometry). These subjects were excluded, since normal spirometry was a prerequisite for inclusion in this study. Minimal emphysema or chronic bronchitis may exist without significantly modifying the FEV1/FVC ratio. However, these changes would predominantly affect small airways, which, in adults, contribute marginally to total Raw. The range of values reported, similar or even lower to that of younger nonsmoking or never-smoking adults, shows that previous smoking apparently does not significantly affect Zrs parameters in older subjects with normal spirometric values. In fact, previous studies show that $Z$ rs values in smokers do not differ significantly from those of nonsmokers [17, 22, 41]. 
In summary, the present study provides reference values for airway resistance by the forced oscillation technique in older subjects. In this age group, height was the best predictor of respiratory impedance parameters. Resistance and resonant frequency values were significantly higher in older females, probably because of sex-related differences in lung volumes. Conversely, resistance values tended to be lower than reported in younger subjects. Distention of the airways, because of the age-related increase in functional residual capacity and the decrease in compliance of the respiratory system, are plausible explanations for lower resistance values in this age group. Further studies are needed to explore the potential clinical contribution of forced oscillation technique in detecting and monitoring obstructive lung disease in the very old.

\section{APPENDIX}

Predictive equations for respiratory impedance variables derived from multiple regression analysis (table 4; height in $\mathrm{m}$; weight in $\mathrm{kg}$; male $=1$; female $=0$ ):

Residual standard deviation (RSD): 0.236

$$
\begin{aligned}
& \ln \left(R_{4}-16\right)=-(0.003 \times \text { age })-(0.188 \times \text { sex }) \\
& -(0.653 \times \text { height })+(0.007 \times \text { weight })-0.491
\end{aligned}
$$

RSD: 0.216

$$
\begin{aligned}
& \ln (R \mathrm{M})=-(0.004 \times \text { age })-(0.203 \times \text { sex }) \\
& -(0.519 \times \text { height })+(0.005 \times \text { weight })-0.467
\end{aligned}
$$

RSD: 0.019

$$
\begin{gathered}
\text { FN }(\mathrm{Hz})=1 /((0.011 \times \text { sex })+(0.062 \times \text { height }) \\
-(0.001 \times \text { weight })+0067)
\end{gathered}
$$

\section{REFERENCES}

1 Parameswaran K, Hildreth A, Chadha D, Keaney N, Taylor I, Bansal S. Asthma in the elderly: underperceived, underdiagnosed and undertreated; a community survey. Respir Med 1998; 92: 573-577.

2 Mahler D. Chronic obstructive pulmonary disease. In: Mahler D, ed. Pulmonary disease in the elderly patient. New York, Marcel Dekker Inc, 1993; pp. 159-183.

3 Carvalhaes-Neto N, Lorino H, Gallinari C, et al. Cognitive function and assessment of lung function in the elderly. Am J Respir Crit Care Med 1995; 152: 1611-1615.

4 Sherman CB, Kern D, Richardson ER, Hubert M, Fogel BS. Cognitive function and spirometry performance in the elderly. Am Rev Respir Dis 1993; 148: 123-126.

5 Janssens JP, Nguyen MC, Herrmann FR, Michel JP. Diagnostic value of respiratory impedance measurements in elderly subjects. Respir Med 2001; 95: 415-422.

6 Delacourt C, Lorino H, Herve-Guillot M, Reinert P, Harf A, Housset $\mathrm{B}$. Use of the forced oscillation technique to assess airway obstruction and reversibility in children. Am J Respir Crit Care Med 2000; 161: 730-736.
7 Johnson B, Beck K, Zeballos R, Weisman I. Advances in pulmonary laboratory testing. Chest 1999; 116: 1377-1387.

8 Navajas D, Farre R. Forced oscillation technique: from theory to clinical applications. Monaldi Arch Chest Dis 2001; 56: 555-562.

9 Oostveen E, MacLeod D, Lorino H, et al. The forced oscillation technique in clinical practice: methodology, recommendations and future developments. Eur Respir J 2003; 22: 1026-1041.

10 American Thoracic Society. Standardization of spirometry: 1994 update. Am J Respir Crit Care Med 1995; 152: 1107-1136.

11 Siafakas NM, Vermeire P, Pride NB, et al. Optimal assessment and management of chronic obstructive pulmonary disease (COPD). The European Respiratory Society Task Force. Eur Respir J 1995; 8: 1398-1420.

12 Quanjer P, Tammeling G, Cotes J, Pederson O, Peslin R, Yernault J. Lung volumes and forced expiratory flows. Eur Respir J 1993; 6: Suppl. 16, 5-40.

13 Clement J, Landser FJ, Van de Woestijne KP. Total resistance and reactance in patients with respiratory complaints with and without airways obstruction. Chest 1983; 83: 215-220.

14 Lorino A, Atlan G, Lorino H, Zanditenas D, Harf A. Influence of posture on mechanical parameters derived from respiratory impedance. Eur Respir J 1992; 5: 1118-1122.

15 Peslin R, Duvivier C, Gallina C, Cervantes P. Upper airway artifact in respiratory impedance measurements. Am Rev Respir Dis 1985; 132: 712-714.

16 Van de Woestijne K, Desager K, Duiverman E, Marchal F. Recommendations for the measurement of respiratory input impedance by means of the forced oscillation method. Eur Respir Rev 1994; 4: 235-237.

17 Gimeno F, van der Weele LT, Koeter GH, van Altena R. Forced oscillation technique. Reference values for total respiratory resistance obtained with the Siemens Siregnost FD5. Ann Allergy 1992; 68: 155-158.

18 Gimeno F, Van der Weele L, Koëter G, de Monchy J, van Altena R. Variability of forced oscillation (Siemens Siregnost FD5) measurements of total respiratory resistance in patients and healthy subjects. Ann Allergy 1993; 71: 56-60.

19 Rotger M, Peslin R, Farre R, Duvivier C. Influence of amplitude, phase, and frequency of pseudorandom pressure input on impedance data and their variability. Eur Respir Rev 1991; 1: 178-182.

20 Van der Elshout F, Van de Woestijne K, Folgering $\mathrm{H}$. Variations of respiratory impedance with lung volume in bronchial hyperreactivity. Chest 1990; 98: 358-364.

21 Neild J, Twort C, Chinn S, et al. The repeatability and validity of respiratory resistance measured by the forced oscillation technique. Respir Med 1989; 83: 111-118.

22 Landser FJ, Clement J, Van de Woestijne KP. Normal values of total respiratory resistance and reactance determined by forced oscillations: influence of smoking. Chest 1982; 81: 586-591.

23 Pasker H, Mertens I, Clement J, Van de Woestijne K. Normal values of total respiratory input resistance and reactance for adult men and women. Eur Respir Rev 1994; 4: 134-137. 
24 Pasker HG, Schepers R, Clement J, Van de Woestijne KP. Total respiratory impedance measured by means of the forced oscillation technique in subjects with and without respiratory complaints. Eur Respir J 1996; 9: 131-139.

25 Govaerts E, Cauberghs M, Demedts M, Van de Woestijne K. Head generator versus conventional technique in respiratory input impedance measurements. Eur Respir Rev 1994; 4: 143-149.

26 Rigau J, Burgos F, Hernandez C, Roca J, Navajas D, Farre R. Unsupervised self-testing of airway obstruction by forced oscillation at the patient's home. Eur Respir J 2003; 22: 668-671.

27 Navajas D, Farré R. Oscillation mechanics. Eur Respir Mon 1999; 4: 112-140.

28 Farre R, Ferrer M, Rotger M, Navajas D. Servocontrolled generator to measure respiratory impedance from 0.25 to $26 \mathrm{~Hz}$ in ventilated patients at different PEEP levels. Eur Respir J 1995; 8: 1222-1227.

29 Govaerts E, Demedts M, Van de Woestijne KP. Total respiratory impedance and early emphysema. Eur Respir J 1993; 6: 1181-1185.

30 Reisch S, Schneider M, Timmer J, Geiger K, Guttmann J. Evaluation of forced oscillation technique for early detection of airway obstruction in sleep apnea: a model study. Technol Health Care 1998; 6: 245-257.

31 Bohadana A, Peslin R, Megherbi S, et al. Doseresponse slope of forced oscillation and force expiratory parameters in bronchial testing. Eur Respir J 1999; 13: 295-300.

32 Crapo R, Morris A, Clayton P, Nixon C. Lung volumes in healthy non-smoking adults. Bull Eur Physiopathol Respir 1982; 18: 419-425.
33 Vooren $\mathrm{PH}$, van Zomeren BC. Reference values of total respiratory resistance, determined with the "opening" interruption technique. Eur Respir J 1989; 2: 966-971.

34 Chowienczyk PJ, Lawson CP, Lane S, et al. A flow interruption device for measurement of airway resistance. Eur Respir J 1991; 4: 623-628.

35 Delacourt C, Lorino H, Fuhrman C, et al. Comparison of the forced oscillation technique and the interrupter technique for assessing airway obstruction and its reversibility in children. Am J Respir Crit Care Med 2001; 164: 965-972.

36 Janssens JP, Pache JC, Nicod LP. Physiological changes in respiratory function associated with ageing. Eur Respir J 1999; 13: 197-205.

37 Butler J, Caro CG, Alcala R, Dubois AB. Physiological factors affecting airway resistance in normal subjects and in patients with obstructive respiratory disease. J Clin Invest 1960; 39: 584-591.

38 Crapo RO, Morris AH, Clayton PD, Nixon CR. Lung volumes in healthy nonsmoking adults. Bull Eur Physiopathol Respir 1982; 18: 419-425.

39 Pelzer AM, Thomson ML. Effect of age, sex, stature, and smoking habits on human airway conductance. J Appl Physiol 1966; 21: 469-476.

40 Stuckelberger A, Höpflinger F. Ageing in Switzerland at the dawn of the XXIst century: main results and findings of the National Research Program on Ageing. Swiss National Science Foundation, ed. Bern, Swiss National Science Foundation, 2000.

41 Peslin R, Hannhart B, Pino J. Mechanical impedance of the chest in smokers and non-smokers (author's translation). Bull Eur Physiopathol Respir 1981; 17: 93-105. 